\title{
Inequality and informality in transition and emerging
} countries

\section{A bidirectional relationship between informality and inequality exists; in transition and emerging countries, higher informality decreases inequality}

Keywords: informality, inequality, shadow economy

\section{ELEVATOR PITCH}

Higher inequality reduces capital accumulation and increases the informal economy, which creates additional employment opportunities for low-skilled and deprived people. As a result, informal employment leads to beneficial effects on income distribution by providing sources of income for unemployed and marginalized workers. Despite this positive feedback, informality raises problems for public finances and biases official statistics, reducing the effectiveness of redistributive policies. Policymakers should consider the links between inequality and informality because badly designed informality-reducing policies may increase inequality.

\section{KEY FINDINGS}

\section{Pros}

๑ The informal economy increases human capital accumulation due to the provision of employment opportunities to low-skilled workers, especially in developing countries.

๑ Informal activities that provide employment to lower-income workers likely lead to beneficial effects on income distribution.

- Informal activities can help to maintain economic activity when rent-seeking and excessive regulatory burdens raise the cost of formal production.
Informality vs inequality in emerging and transition countries, 2006-2018

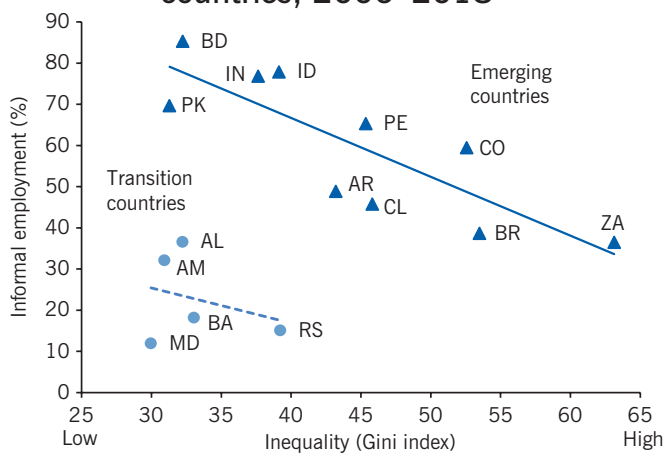

Source: World Development Indicators (average 2006-2018): Gini index (World Bank estimate) [SI.POV.GINI]; Informal employment (\% of total nonagricultural employment) [SL.ISV.IFRM.ZS] (WDI - version September 2020). I Z A

\section{Cons}

- Higher inequality decreases human and physical capital accumulation, which may increase informality.

- Widespread informality can lead to severe problems for public finances and reduce the resources available for redistributive policies, potentially leading to less effective redistribution.

- Public policies aimed at reducing informality can increase inequality.

- Informal workers can be locked into informal jobs, thus decreasing their social mobility.

$\ominus$ Due to measurement errors in informality and inequality data, empirical analyses on this issue should be interpreted with caution.

\section{AUTHOR'S MAIN MESSAGE}

Analyzing the relationship between inequality and informality is challenging due to an influential third factor: the official economy. Omitting the different causal mechanisms between these three variables may inhibit effective policy making. The informal economy can provide sources of income and opportunities to accumulate human capital for marginalized workers. For transition and emerging countries, this means that informality-reducing policies based only on tax reduction and enhanced enforcement of tax and regulatory rules may lead to disappointing economic outcomes, such as increased inequality, and higher rates of long-term unemployment. 


\section{MOTIVATION}

Over the past two decades, empirical research has investigated the relationship between income inequality and informality. These analyses have shown that various causal mechanisms may operate in both directions. Inequality and informality, and the links between the two, are important to society because they affect economic growth and the quality of institutions. The composition of the informal economy (i.e. underground and informal sector production) affects the consequences of inequality on informality, and vice versa; in turn, this relationship influences the design and effects of public policy. For transition and emerging countries, where the informal sector is expected to be predominant compared to underground production, uncompromising policy measures intended to reduce informality by increasing enforcement may have largely detrimental effects (e.g. increase inequality and decrease overall economic growth).

\section{DISCUSSION OF PROS AND CONS}

\section{The definition of the informal economy}

Several classifications and labels have been used to define the informal economy. These numerous and often inconsistent definitions are not just a result of the unobserved nature of the issue but are also attributable to the different aims and policy perspectives that motivate investigations into the subject. As a result, it is quite common in the literature that adjectives such as informal, shadow, hidden, second, unrecorded, unofficial, and unobserved are used alongside terms such as economy, sector, market, production, and GDP. However, these labels often refer to distinct phenomena and should be used appropriately to avoid misunderstandings.

\section{Definitions of non-observed economies (NOE)}

For analytical purposes, the OECD (2014) proposes a simplification of the seven sources of non-exhaustiveness for GDP estimates that were proposed by Eurostat's (2005) "Tabular approach to exhaustiveness," in five types of NOE adjustments:

Underground production: activities that are productive and legal but deliberately concealed from public authorities to avoid payment of taxes or compliance with regulations;

Illegal production: productive activities that generate goods and services forbidden by law or that are unlawful when carried out by unauthorized procedures;

Informal sector production: productive activities conducted by unincorporated enterprises, in the household sector or other units that are unregistered and/or less than a specified size in terms of employment, and that have some market production;

Household production for own/final use: productive activities that result in goods or services consumed or capitalized on by the households that produced them;

Statistical deficiency: all productive activities that should be accounted for in basic data collection programs but are missed due to deficiencies in the statistical system.

Source: Eurostat. Eurostat's Tabular Approach to Exhaustiveness: Guidelines. Ref. Eurostat/ C1/GNIC/050 EN. Paper from the 5th Meeting of the GNI Committee, July 5-6, 2005; OECD. Statistics Brief, No. 18. Paris: OECD Statistics Directorate, 2014. Online at: http:// www.oecd.org/std/na/Statistics\%20Brief\%2018.pdf 
One recent study tries to reconcile the most used definitions of shadow (or informal) economy in economic research with the concept of the non-observed economy (NOE), which is used in Statistical National Accounting [1]. Two types of NOE adjustments of GDP estimates are particularly relevant here: underground production and informal sector production.

\section{What does the literature say about the relationship between inequality and informality?}

There are several potential channels and economic rationales that may explain how inequality, directly and indirectly, affects informality, and vice versa. Figure 1 displays some of these causal mechanisms that drive the complex relationship between inequality and informality. For the sake of clarity, these cause-effect interactions can be clustered into three groups: the direct effects of inequality on informality through capital accumulation and institutions; the indirect effect of changes in inequality through the formal economy; the feedback effects of informality on income distribution.

Figure 1. Inequality and informality

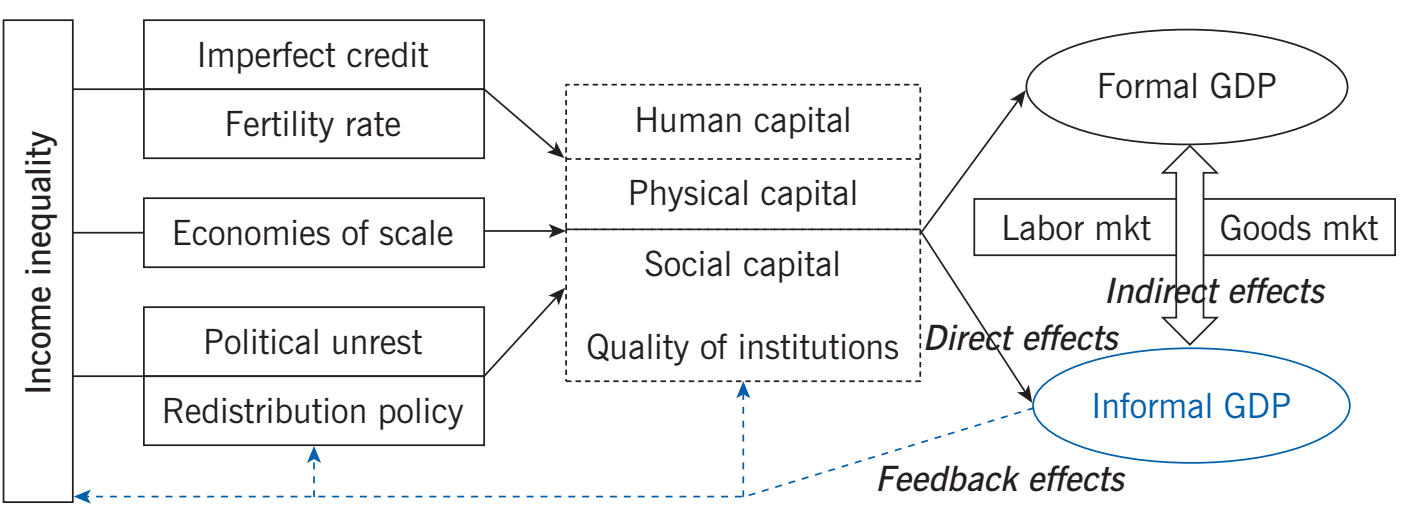

Note: Higher inequality increases informality by reducing human, physical, and social capital accumulation (direct effects); in transition and emerging countries, higher inequality decreases the formal economy and, in turn, increases informality (indirect effects); higher informality may increase inequality by reducing the effectiveness of redistributive policies, or may decrease inequality by providing sources of income for unemployed and marginalized workers (feedback effects).

Source: Author's own illustration.

\section{Direct effect-Credit markets and fertility rates}

The effect of inequality on the accumulation of human capital is the main channel of interaction between inequality and informality, primarily due to its impact on the labor market. In particular, increasing income inequality decreases human capital accumulation due to imperfect capital markets and higher fertility rates. As a result, formal GDP decreases and informal GDP increases. The effect on the formal economy is supported by clear empirical evidence showing that richer people have fewer children than poorer people. Raising children requires parents' time; for poorer families, it is less "expensive" to spend their time raising children than for richer households, as their time is less "valuable" from a monetary perspective. Moreover, income inequality is associated with gender inequality 
and lower female incomes, and the latter is negatively correlated with the fertility rate. As a result, a more unequal distribution of assets leads to a higher fertility rate, and, under the assumption of an imperfect capital market, it reduces productive investments in human capital per capita because families do not have sufficient access to credit [2].

The income distribution may also affect the future growth rate of the informal economy: a larger share of poor and unskilled workers is usually more inclined to accept lower salaries and health and safety standards in the workplace than richer and more skilled workers because they have fewer and qualitatively worse job opportunities, implying that informal economic activity will rise as inequality increases. Moreover, prolonged informal work experience may be associated with social stigma and loss of the human and social capital required for re-employment in the formal economy, leading to situations in which workers become effectively trapped in informal employment.

\section{Direct effect-Economies of scale}

An increase in income inequality decreases physical capital accumulation due to lower domestic aggregate demand and, in turn, economies of scale. As a result, lower physical capital decreases formal GDP and increases informal GDP. The economic intuition for these assertions is that, on the formal side of the economy, greater inequality reduces the aggregate demand for goods and services. Domestic product markets are thus too small to fully develop local industries or to attract foreign direct investment. As a consequence, a more unequal income distribution reduces physical capital accumulation and, in turn, reduces formal GDP. On the informal side of the economy, small-scale enterprises find it easier to hide from public authorities (i.e. underground production) than larger firms do; consequently, lower physical capital accumulation also encourages participation in the informal economy.

\section{Direct effect-Political factors (political unrest, redistribution)}

A first group of models theorizes that a more unequal income distribution causes "political instability" and motivates the poor to engage in crime and disruptive activities. Through these dimensions of socio-political unrest, high economic disparities, which reduce social capital and institutional quality, diminish overall productivity and economic growth in the official economy. On the hidden side of the economy, considering that taxpayers systematically adjust their evasion levels according to their satisfaction levels with public policy and the quality of their relationship with authorities, it is expected that by decreasing tax morale (i.e. intrinsic non-pecuniary motivation to pay taxes), increasing social stigma, and, in general, diminishing citizens' attitudes toward the state, higher income inequality causes higher levels of underground production (i.e. tax evasion) and illegal activities.

A second group of models suggests that more inequality increases social demand for redistribution throughout the political process. Typically, transfer payments (e.g. benefit payments or subsidies) and associated progressive taxation will distort economic decisions, and through this channel, inequality reduces both the growth of the official economy and, via higher income tax rates, encourages official business activities to move into the untaxed informal economy. Hence, inequality increases the size of underground production.

\section{Indirect effects-Interactions between the informal and formal economy}

Analysis of the relationship between the formal and informal economy is one of the most relevant and challenging issues in this literature. However, the effect of informality on 
economic growth remains considerably ambiguous, theoretically and empirically. The correlation between these two "sides" of the economy may be both negative, "harmful" hypothesis, and positive, "benign" hypothesis.

According to the "harmful" hypothesis, the informal economy harms the formal economy because of the misallocation of private and public resources. This inefficiency has a twofold nature: a market inefficiency, due to unfair competition of the free-riding informal activities; and a technical inefficiency, due to the choice to operate below a certain detection threshold, therefore, informal activities lack the necessary scale to produce efficiently. In particular, the need to hide informal activities from public authorities leads to: limited protection of property rights that increases both entrepreneurial and credit risk; being forced to operate at suboptimal scale; ownership being constrained to family components or single individuals; and a greater probability of becoming the victim of extortion and corruption. While at the firm level the choice to work informally may be rational (e.g. as the cost advantage gained by avoiding taxes and regulations more than offsets a firm's productivity and scale), at the social level this decision reduces overall market efficiency.

According to the "benign" hypothesis, informal activities provide cheap goods and services, which increase the level of competition faced by regular enterprises. By the same token, more formal production increases the demand for goods and services produced by unobserved activities. Indeed, various studies have shown that a reverse causality can occur, that is, the informal economy has a beneficial effect on economic development. Focusing on transition economies, the most obvious benefit of the informal economy is that it helps maintain economic activity when rent-seeking (the extraction of uncompensated value from others without making any contribution to productivity) and corruption raise the cost of formal production [3]. Informal activities can increase competition in the formal economy and impose upper bounds on governmental activities and regulatory burdens. They may contribute to an increase in financial resources and provide entrepreneurial experiences that are important, especially in transition and emerging countries. Thus, a positive relationship between informality and the formal economy is also theoretically and empirically possible.

Empirical research that may rationalize these contradictory findings shows that while informal activities boost economic growth in developed economies, they reduce the growth rate of the official GDP in developing countries [4]. As a result, adequate knowledge of both sectoral composition and degree of economic development are critical in determining the correlation (whether positive or negative) between the informal and formal economy and, as a consequence, the indirect effects of inequality on informality, and vice versa.

\section{Feedback effects of the informal economy on income inequality}

Several channels can explain how the informal economy has reverse effects on income inequality. On the one hand, a sizable level of informality reduces government revenue and intensifies pressure on public finances, which, in turn, reduces the quality and quantity of publicly provided goods and redistributive policies [5]. In particular, a growing informal economy presents problems because informal workers and producers do not pay taxes, but rather free ride on public services; this is a source of inefficiency in the public provision and allocation of private and public resources. With particular reference to transition 
and emerging countries, lower tax revenues impede adequate public investment in physical (e.g. infrastructure), human (e.g. education, research), and social (e.g. welfare programs, judicial system) capital. With respect to social issues, the informal economy exacerbates a lack of trust in official institutions, feeds resentment among citizens, and favors corruption and illegal activities. These consequences all contribute to a reduction in institutional quality.

Similarly, the informal economy reduces tax revenues, thereby diminishing the effectiveness of a government's redistributive policies. Evidence suggests that large levels of informality coincide with less redistribution and more income inequality [6]. Research on transition economies suggests that the very presence of an informal economy typically leads to a smaller number of competing foreign enterprises. This lesser threat of competition from foreign firms reduces allocative efficiency and innovation, facilitates rent-seeking activity, and allows for further consolidation of monopoly power, leading to higher profits for firms at the expense of consumers, thereby increasing inequality [3]. On the other hand, the informal economy often absorbs the unemployed from the formal economy, serving as a source of income and human capital accumulation for excluded and unskilled workers. In this sense, informal activities provide employment to those with lower incomes and fewer job opportunities; therefore, informality may have a beneficial effect on income distribution. These contrasting effects may provide the rationale for empirical evidence that describes a statistically insignificant relationship between the size of the informal economy and the Gini coefficient, which is a well-respected measure of inequality [3]. In particular, informality and inequality develop in the same direction (i.e. they rise together or fall together) if informal income is higher for richer individuals (i.e. underground production); otherwise, inequality decreases while informality increases, and vice versa, in the case where informal income is higher for poorer individuals (i.e. informal sector production).

\section{What does the empirical literature find?}

The prevalent view in the empirical literature is that higher inequality increases the size of the informal economy, though some studies find a statistically insignificant correlation (see [2] for an overview). However, variance in outcomes is normally attributed to data limitations, regional differences, and bias from measurement errors. On the latter, additional to the rough calculation of informality, a source of bias that undermines the reliability of empirical findings is that income inequality is mainly measured using "declared/regular/formal" incomes [7]. The very presence of an informal economy biases the estimation of inequality indexes, because unrecorded income may not be uniform across the income distribution spectrum [7]. This means that as the share of unrecorded income earned by the poor increases, the estimate of income inequality will be more biased (underestimated), and vice versa.

When focusing on transition countries, the first attempt to document a relationship between income inequality and the relative size of the informal economy was based on estimates of informality calculated by the electricity method for the years 1989-1995 in 17 transition economies [8]. This research found a positive correlation between income inequality and the informal economy. However, this result has not been corroborated by more recent empirical analyses. For example, a statistically insignificant relationship between the size of the informal economy and the Gini coefficient was found using a 
larger data set of transition countries [3]. This study was based on macro-estimates of the informal economy in 25 transition countries during the period 1990-1997, calculated using a "modified" electricity method. Inconclusive findings were also obtained using microdata from the Serbian labor market, extracted by the Living Standard Measurement Surveys. In this case, informality played an increasingly important role in explaining earnings inequality in 2007, but not in 2002 [9]. Indefinite results on the relationship between informality and inequality were also found in panel regressions for 16 transition countries [10]. This research concluded that the statistical significance of the correlation between informality and inequality depended on the estimation method and the time period considered to estimate informality. Specifically, informality and inequality showed a statistically insignificant relationship if the size of the informal economy was estimated by the currency approach, modified electric consumption, or was derived from statistics compiled by national agencies. Conversely, if estimates of informality were calculated using the MIMIC ("multiple indicators multiple causes") approach, then a positive correlation with income inequality occurred. This evidence concurs with most of the literature, which points out that the correlation (whether it is positive or negative) between inequality and informality is affected by the problems of working with unreliable estimates of the informal economy and the effects of other variables and circumstances [8], as summarized and developed in the previous paragraph and in Figure 1.

An important strand of this literature investigates the effect of informality on inequality in emerging countries and concludes there is a positive income effect of the earnings of informal workers on the income distribution. For instance, a study on the South African informal economy has estimated the "per job" impact of informal jobs on overall poverty reduction relative to the impact of a formal job. Despite lower incomes in informal employment, the earnings of an informal worker have between $54 \%$ and $84 \%$ of the poverty-reducing impact compared with earnings from a formal sector job [11].

Recent research has focused on the dynamic endogenous relationships between income inequality and the informal economy while controlling for the influence of the formal economy [7]. The study shows a bidirectional positive relationship between informality and inequality using a data set of 144 countries observed over the period 1960-2009. According to this analysis, the nature of the causal relationship varies over time. While in the short and medium term (i.e. less than 15 years) more inequality has an insignificant effect on the informal economy, it increases informality after the first 15 -year period. As the causal relationship reverses (i.e. from informality to inequality), the opposite occurs: a greater informal economy increases inequality in the short and medium term, while this effect disappears after 15 years.

Some scholars attempt to rationalize the statistically insignificant correlations for transition countries (e.g. [3], [9], [10]) by hypothesizing a non-linear (concave upwards) relationship between inequality and informality due to credit market imperfections and entry costs [2]. The economic intuition is that, on the one hand, in the presence of credit market imperfections and significant entry costs of starting a formal business activity, high inequality generates higher demand for loans. Thereby, high inequality increases the financial costs for those who must take on debt to start their activities, assuming that, all other factors being held constant, higher demand for loans increases loan interest rates and transaction costs. Accordingly, (very) high inequality increases the informal economy by increasing the financial costs associated with formal business activity. On 


\section{Informal economy estimation methods}

Estimates of the informal economy can be calculated using two main approaches: macroeconometric and national accounting methods.

Macroeconometric methods are usually placed into three groups:

Direct methods are based on contact with or observations of persons and/or firms, to gather direct information about undeclared income/production. This includes, for instance, analyses of data collected by auditing tax returns and crime statistics (judicial method); "ad hoc" sample surveys designed to estimate the informal economy, or by using existing household survey programs, e.g. the Living Standards Measurement Study of the World Bank's Development Data Group (Survey method); and by experiments.

Indirect methods try to determine the size of informality, by measuring the "traces" that it leaves in official statistics. They are often called "indicator" approaches and use mainly macroeconomic data. This includes measuring discrepancies (e.g. discrepancy between national expenditure and income statistics; discrepancy between the official and actual statistics of the labor force); monetary methods (e.g. transaction approach; the currency demand (or cash-deposit ratio) approach); the physical input method or electricity method.

The Model or MIMIC approach is based on the statistical theory of latent variables (variables that are not directly observed but are rather inferred (through a mathematical model) from other variables that are observed (directly measured)), which considers several causes and several indicators of the informal economy. It is considered as an "unobservable/ latent variable."

The national accounting method to achieve exhaustiveness or the "Tabular approach to exhaustiveness" is applied by national statistical institutes to appropriately measure and include in the GDP estimates of the non-observed activities. It combines different data sources and adjustment methods in accordance with the source of non-exhaustiveness (i.e. lack of the coverage and consistency of national accounts). In general, it includes the nonobserved economy in GDP estimates compiled by the production approach using different complex procedures, e.g. based on supply (e.g. labor input), demand, income, or commodity.

the other hand, extremely low inequality is associated with excessive redistribution and, in turn, an excessive income tax burden. Such a high income tax burden makes working in the formal economy less attractive than working in the (untaxed) informal economy (i.e. underground production). Accordingly, (very) low inequality resulting from an excessive tax burden on formal business activity increases the extent of the informal economy [2].

\section{Why the relationship between inequality and informality may depend on the composition of the informal economy}

In (highly) developed countries-countries with an adequate endowment of human and physical capital, good institutions, and a suitable size of the declared tax basethe informal economy mainly takes the form of underground production (i.e. activities performed with the deliberate intention of evading the payment of taxes or social security contributions, or infringing labor legislation or other regulations) rather than informal sector production (i.e. units that typically operate with little or no division between labor and capital as factors of production and on a small scale). This implies that the 
negative externalities due to unfair competition and bias of official statistics associated with underground production are larger than the positive effects related to the idea of informality as a source of income and human capital accumulation for excluded workers and the poor, as is typical of informal production. Consequently, governments of developed economies may effectively reduce informality without significantly increasing inequality, and vice versa, by combating the causes of underground production, such as inefficiency in public administration, weak tax enforcement, and reducing excessive tax burdens and regulations. This is possible because underground production mainly arises as a result of the overburden that businesses suffer in terms of taxation and bureaucracy.

In developing countries-countries with lower capital endowment and institutional quality-informal production is usually the predominant component of the informal economy. A less developed economic system makes the informal economy a natural "social buffer" for low-skilled workers and marginalized people (e.g. illegal immigrants, involuntary unemployed). Production within the informal sector generates and distributes a source of income that will not be created in the formal economy because informal firms cannot compete with the much more productive formal firms [12]. Consequently, informal production has both a positive effect on income distribution and generates positive externalities for formal activities via both higher demand for goods and services purchased from informal sector participants and greater human capital accumulation. Unlike in highly developed countries, for less developed economies (e.g. transition and emerging), an increase in tax enforcement may be counter-effective because the subsequent reduction in informal production is not compensated by a corresponding increase in the tax base. The economic rationale is that these marginal informal activities do not have sufficient human and physical capital endowment or adequate access to financial systems to survive in a competitive formal market. As such, in less developed countries reducing informality by tightening business regulations and tax enforcement is expected to increase inequality, reduce capital accumulation, and lower demand for formal goods.

\section{LIMITATIONS AND GAPS}

Analyzing the sign (whether positive or negative) of the relationship between inequality and informality empirically is challenging due to measurement errors in informality and inequality, the varied nature of the informal economy, which is linked to the country's economic development, and differences in the time horizons (long-term versus shortterm) of the analyses. While for the last two concerns scholars are finding noteworthy solutions (e.g. [7]), on the reliability of aggregate measures of the informal economy the problem is difficult to solve, and different methods yield different results. Accordingly, it is widely accepted by most scholars that all estimates of the informal economy are "vulnerable" and no one can really claim to be confident in the full reliability of their estimates, regardless of which method is used. Concerning the measure of inequality, there exists a further source of bias due to the possibility that tax evaders under-report their income in household surveys that are used to determine income inequality, likely reporting the same (lower) figures as they declare in their tax returns. Given that informal income is not uniformly distributed along the income spectrum, empirical investigations on the relationship between informality and inequality are challenging due to the existence of two sources of correlated measurement biases. In other words, there is a measurement bias in inequality index estimation-due to asymmetrical distribution of the informal 
income along with the population-and a further source of measurement errors related to estimating the size of the informal economy. Moreover, these two variables' biases conflate potential errors in the other, because the measurement errors in inequality are also correlated to the size of the informal economy.

\section{SUMMARY AND POLICY ADVICE}

The predominant view in the literature is that high inequality is harmful for economic growth and increases the informal economy. However, the effect of informality on many aspects of a country's economic and social life can be both negative and positive; therefore, it is hard to generalize the overall effect of inequality on informality, and vice versa.

What is clear is that the role and relative importance of informal and underground production strongly affect the consequences of inequality on informality (and vice versa) and, in turn, influence the design and consequences of public policy. This emphasizes the need for further research, particularly for focused normative analyses on informality that assess groups of similar economies (e.g. OECD, transition, developing).

The primary practical takeaway is that policymakers should differentiate the design of informality- and/or inequality-reducing policies in accordance with the characteristics of the informal economy (i.e. the relative size of the informal sector production versus underground production). These policies should facilitate the transition of workers and economic units from the informal to the formal economy to avoid an increase in income inequality. Effective policies to speed up the transition to the formal economy consist of a balanced approach of incentives (e.g. reducing the tax and regulatory burden for independent workers and micro-enterprises; facilitating their access to microcredit; offering financial incentives for promoting school attendance) and compliance measures.

If they fail to do this, even well-designed policies aimed only at reducing inequality or only at combating informality may end up being detrimental to the overall economy.

\section{Acknowledgments}

The author would like to thank an anonymous reviewer and the IZA World of Labor editors for helpful suggestions on earlier drafts. Version 2 of the article updates the Illustration on p. 1, adds research on the effect of informality on inequality in emerging countries, and adds new policy advice and new "Key references" [7], [11].

\section{Competing interests}

The IZA World of Labor project is committed to the IZA Code of Conduct. The author declares to have observed the principles outlined in the code.

\section{(C) Roberto Dell'Anno}




\section{REFERENCES}

\section{Further reading}

ILO. Women and Men in the Informal Economy: A Statistical Picture. Third Edition. Geneva: International Labour Office, 2018.

Schneider, F., and D. H. Enste. The Shadow Economy. An International Survey. Second Edition. Cambridge: Cambridge University Press, 2013.

\section{Key references}

[1] Dell'Anno, R. "Analyzing the determinants of the shadow economy with a 'separate approach.' An application of the relationship between inequality and the shadow economy." World Development 84 (2016): 342-356.

[2] Dell'Anno, R. "Inequality, informality and credit market imperfections." Macroeconomic Dynamics 22:5 (2018): 1184-1206.

[3] Eilat, Y., and C. Zinnes. "The shadow economy in transition countries: Friend or foe? A policy perspective." World Development 30:7 (2002): 1233-1254.

[4] Schneider, F. "Shadow economies around the world: What do we really know?" European Journal of Political Economy 21:3 (2005): 598-642.

[5] Enste, D. H. "Shadow economy and institutional change in transition countries." In: Belev, B. (ed.). The Informal Economy in the EU Assessment Countries: Size, Scope, Trends and Challenges of the Process of EU-Enlargement. Sofia: Center for Study of Democracy, 2003.

[6] Chong, A., and M. Gradstein. "Inequality and informality." Journal of Public Economics 91:1-2 (2007): 159-179.

[7] Berdiev, A. N., and J. W. Saunoris. "On the relationship between income inequality and the shadow economy.” Eastern Economic Journal 45 (2019): 224-249.

[8] Rosser, J. B., M. V. Rosser, and E. Ahmed. "Income inequality and the informal economy in transitions economies." Journal of Comparative Economics 28:1 (2000): 156-171.

[9] Krstić, G., and P. Sanfey. "Earnings inequality and the informal economy." Economics of Transition 19:1 (2011): 179-199.

[10] Dell'Anno, R., and O. H. Solomon. "Informality, inequality and ICT in transition economies." Eastern European Economics 52:5 (2014): 3-31.

[11] Rogan, M., and P. Cichello. "(Re)conceptualizing poverty and informal employment." In: Chen, M., and F. Carré (eds). The Informal Economy Revisited: Examining the Past, Envisioning the Future. London: Routledge, 2020.

[12] La Porta, R., and A. Shleifer. "Informality and development." Journal of Economic Perspectives 28:3 (2014): 109-126.

\section{Online extras}

The full reference list for this article is available from:

https://wol.iza.org/articles/inequality-and-informality-in-transition-and-emerging-countries

View the evidence map for this article:

https://wol.iza.org/articles/inequality-and-informality-in-transition-and-emerging-countries/map 